\title{
Legislative Bargaining with Reconsideration
}

\author{
Daniel Diermeier* Pohan Fong ${ }^{\dagger}$
}

Draft: January, 2008

Please do not distribute without permission.

\begin{abstract}
We present a dynamic model of legislative bargaining in which policymaking proceeds until the agenda setter has no more incentive to make a new proposal to replace the previously approved policy. We characterize the stationary equilibria of the game and show that in a class of pure-strategy equilibria, a majority of voters without proposal power have an incentive to protect each others' benefits to secure their own long-term bargaining positions in the legislature. As a consequence, the value of proposal power is constrained. In an extended version of the model that includes public goods production we show that the lack of commitment due to the possibility of reconsideration enhances policy efficiency.
\end{abstract}

*Department of Managerial Economics and Decision Sciences and Ford Motor Company Center for Global Citizenship, Kellogg School of Management, Northwestern University.

${ }^{\dagger}$ Department of Economics, Concordia University and Ford Motor Company for Global Citizenship, Kellogg School of Management, Northwestern University. 


\section{Introduction}

Since the seminal paper by Baron and Ferejohn (1989), legislative institutions have been extensively explored and legislative bargaining games have been widely applied in positive theory of policymaking and comparative models of political institutions. In all variants of the Baron-Ferejohn model, a proposer is selected according to a commonly known rule, e.g. random selection with equal probability or proportional to seat shares. He then proposes a policy or an allocation of benefits to a group of voters. According to a given voting rule, the proposal is either accepted or rejected. ${ }^{1}$ If the proposal is accepted, the game ends and all legislators receive payoffs as specified by the accepted proposal. Otherwise, another proposer is selected, and so on. This process continues until a proposal is accepted or the game ends. The stationary equilibria of Baron-Ferejohn model predict that the legislator with proposal power will propose a minimal winning coalition consisting of himself and the "cheapest" set of voters necessary to ensure acceptance. All other voters will receive a payoff of zero. The amounts given to the coalition partners equal the coalition partners' expected payoffs (or continuation values) if the proposal is rejected and the bargaining continues. The proposer will always choose as coalition partners the voters with the lowest continuation values. The division of spoils will in general be highly unequal, especially if the legislators are very impatient.

Subsequently, the model is extended to a dynamic legislative bargaining game in which a default policy is endogenously determined (Baron 1996). ${ }^{2}$ This approach is characterized by the assumption that the policy chosen in the current period will serve as the status quo in the future periods. This approach is particularly important in the study of government budgets. In modern democratic countries a majority proportion of total government spending is conducted in the form of entitlement programs. For example, in 2007 the U.S. government spent 586 million dollars on social security, 394.5 million dollars on medicare, 276.4 million dollars on medicaid, 367 million dollars on unemployment insurance and other welfare programs, and 72.6 dollars on veteran subsidy. Together these entitlement programs composed more than 60 percent of the total budget of 2.8 trillion dollars. In entitlement programs benefits are distributed and once enacted, they are in effect until they are re-

\footnotetext{
${ }^{1}$ This is the case of a "closed rule". Under an open rule other legislators may be selected to propose amendments.

${ }^{2}$ See Duggan and Kalandrakis (2007) for an extensive survey of this literature.
} 
formed in subsequent legislative periods. In many cases, e.g. the U.S. Social Security Act of 1935, beneficiaries can sue the government if benefits are with-held.

With a one-dimensional policy space and single-peaked preferences, Baron (1996) shows that, in the long run, the policy will converge to the policy alternative preferred by the median legislator. Baron and Herron (2003) extend the model to include a multidimensional policy space. Kalandrakis $(2004 ; 2007)$ provides a formal analysis of the paradigmatic case in a divide-the-dollar setting. He shows that there exist stationary equilibria where, in the long run, every proposer captures the entire benefits. Battaglini and Coate (2007; 2008) apply the dynamic legislative bargaining games to study collective choice of public investment and public debt.

Subsequently, various other legislative bargaining models have been proposed. The model most relevant to our paper is Bernheim, Rangel and Rayo (2006) who examine legislative policy making in institutions with agenda setting and an evolving default policy. A default policy is defined as the policy that will be implemented at the end of the legislative period unless it is replaced by a new policy that then becomes the new default policy. Bernheim, Rangel and Rayo (2006) consider a distributive politics framework with ex ante known, finitely many rounds of proposal-making and voting. They show that the last proposer is able to pass his favorite policy under relatively weak conditions. As a consequence, the final policy outcome is highly unequal, and the last proposer is able to obtain his ideal policy.

Our paper is in part motivated by recent empirical work that suggests limits to the proposal power predicted by the Baron-Ferejohn model. First, Knight (2005) recently tested the closed rule Baron-Ferejohn model using US data on the allocation of congressionally earmarked transportation projects across electoral districts. ${ }^{3}$ The evidence supports the key qualitative prediction that proposal power is valuable, but shows that it is significantly more constrained than predicted by the theory. Second, McKelvey (1992) and Diermeier and Gailmard (2006) conduct laboratory experiments of the closed rule model. Again, while there is clear evidence of valuable proposal power, it appears far more constrained than predicted by the theory. Battaglini and Palfrey (2007) provide similar results in

\footnotetext{
${ }^{3}$ Knight (2005) considers the closed-rule case only, as the bill proposed by the House Committee on Transportation and Infrastructure was considered under rules that sharply limited the number of amendments under consideration.
} 
an experimental study of a version of the Kalandrakis model in the case of risk averse preferences.

To formally study the constraints of proposal power we propose a different approach that focuses on the non-proposing voters. To analyze this case as cleanly as possible we consider the pure case where these voters have no proposal power at all. Of course, this is not an interesting case in any of the versions of the Baron-Ferejohn model with or without a dynamically changing status quo, as players without proposal power would receive an equilibrium payoff of zero. Indeed, it can be shown (Diermeier and Myerson 1994) that in a divide-the-dollar setting where a player has veto power, but lacks proposal power, while all other players have some proposal power, but no veto power, the veto player receives an equilibrium payoff of zero.

Our theory consists of three key elements. First, reconsideration is allowed and the default policy evolves. In other words, the passage of a proposal does not prevent the legislature from coming back to the same issue at a later date. Rather, it changes the default for subsequent policymaking. This setup is reminiscent of that of Bernheim, Rangel and Rayo (2006).

Second, whereas Bernheim, Rangel and Rayo (2006) assume a fixed and predetermined number of proposal rounds as well as commonly known fixed order of proposers, here the final proposal round is endogenously determined rather than exogenously given. Intuitively, our setup corresponds to the case where policymaking proceeds until any legislator with proposal power has no more incentive to make a new proposal to replace a previously passed bill.

Third, proposal power is concentrated and persistent throughout the legislative session. Our motivation for this assumption is given by our theoretical purpose: To investigate endogenous constraints on proposal power. However, some legislative systems come quite close to this idealized case. For example, comparative scholars have long observed that compared to presidential systems the constitutional features of parliamentary systems lead to high levels of agenda control for the executive, i.e. the cabinet (Doering 1995). In many cases, that power is concentrated within the prime minister. Our single, persistent agenda setter therefore may be interpreted as the prime minister. Importantly, a concentration of proposal power by law does not necessarily lead to valuable proposal power in practice.

Surprisingly, the possibility of reconsideration may put significant limits on proposal 
power even in the case of a single proposer. As we show, it may induce legislators with no proposal power to "protect" the benefits of other non-proposing legislators. This mutual protection is an equilibrium phenomenon born out of pure self-interests. As in the standard model legislators care only about their own benefits, not the benefits of others. However, in equilibrium there is an incentive to protect others as this limits the proposer's ability to play off the voters against each other. Intuitively, non-proposer A protects non-proposer B so that proposer $\mathrm{C}$ cannot use the low reservation value of $\mathrm{B}$ to exploit $\mathrm{A}$. The ex post value of proposal power is therefore constrained. The underlying mechanism can be illustrated by two examples below.

Example 1. Consider a legislature with three players. The first player is assumed to be the agenda setter. The legislature must divide 6 dollars, where each dollar is indivisible. Suppose the initial default is $d=(1,2,3)$, where the $i$-th element of $d$ refers to the amount that goes to the $i$-th player. A default is the policy that will be implemented at the end of the legislative session if no new policy is made in the rest of the session. The agenda setter has sole power to make proposals and initiate reconsiderations. A proposal, once made, is immediately voted in the legislature by majority rule against the default. A policy proposal, once approved in the legislature, serves as the new default and may be subject to reconsideration if the agenda setter chooses to make a new proposal to replace it. The policy that (as default) survives until the end of the legislative session is the final policy outcome.

It is easy to see that in a one-shot Baron-Ferejohn legislative bargaining game under a closed rule, the setter would propose $\widehat{x}=(4,2,0)$. This policy would be approved by the players who receive positive payoffs and rejected by the player who receives nothing. Notice that the last player is fully expropriated since his vote is not needed. However, if the agenda setter is likely to have a chance to reconsider the policy issue and make another proposal, the second player would not accept policy $\widehat{x}$ in equilibrium, even though $\widehat{x}$ gives the second player exactly the same as the default. To see why, consider counterfactually what would happen if this player accepted $\widehat{x}$. In this situation, the agenda setter would have an incentive to reconsider the policy issue and propose $\widehat{x}^{\prime}=(6,0,0)$, which would not be vetoed by the last player, who is indifferent. This implies that the second player would be eventually fully expropriated if he voted for $\widehat{x}$ in the first place. 
By the same logic, the agenda setter is not able to pass any policy that gives the last player, whose vote is not needed, any amount less than 2 dollars. The equilibrium policy outcome is thus $x^{*}=(2,2,2)$, an egalitarian division of the six dollars. In this equilibrium, the second player wants to protect the benefits for the last player, since by doing so the second player secures his long-term bargaining position in the legislature. Note that the value of proposal power is reduced compared to a case without reconsideration even if there is a sole proposer.

Example 2. Consider a legislature with five players. Again, the first player is assumed to be the sole agenda setter. The legislature must divide 10 dollars, where each dollar is indivisible. Suppose the initial default is $d=(0,1,2,3,4)$. Assume the political process is as given in the first example. As before, in one-shot Baron-Ferejohn legislative bargaining under a closed rule, the setter would propose $\widehat{x}=(7,1,2,0,0)$. The last two players are fully expropriated since their votes are not needed. However, if under some institution the agenda setter is likely to have a chance to reconsider the policy issue and make another proposal, players 2 and 3 would not accept policy $\widehat{x}$ in equilibrium. With $\widehat{x}$ as the new default policy, they would be fully expropriated and eventually given nothing.

One possible policy proposal players 2 and 3 would accept in an equilibrium is $x^{*}=$ $(4,2,2,2,0)$. With $x^{*}$ as the new default, the agenda setter would not be able to pass any new policy that gives himself more than 4 dollars. This is because players 2,3 and 4 all have incentives to protect the benefits for one another. If any player $i \in\{2,3,4\}$ was expropriated and given less than 2 dollars, the agenda setter would have incentives to reconsider the policy and ally with both the last player and the expropriated one.

In this equilibrium some voter, player 4 in the example, is not fully expropriated even if his vote is not needed. Players 1 and 2 vote for $x^{*}$ against the initial default, and player 1 even receives more than what he would receive from the default. The value of proposal power is substantially reduced. Out of fear that the agenda setter may use his proposal power to exploit those players with lower reservation values in the future, a group of players take care of one another even if they are self-interested.

Below we develop a general model that captures the intuitions illustrated in the examples. As most of the literature, the focus is on stationary equilibria due to the recursive nature of the game. A stationary equilibrium for dynamic legislative bargaining with an 
endogenous default needs not exist, and, if it does, it is usually associated with mixed strategies as shown in a few recent studies in the literature. ${ }^{4}$ However, in the game considered here, if the probability for reconsideration is sufficiently high, there exists a class of pure-strategy stationary equilibria. ${ }^{5}$ We then characterize these equilibria for a legislature with an arbitrary odd number of members.

In the pure-strategy stationary equilibria, the possibility of reconsideration limits agenda control in the case where proposal power is persistent. This is in marked contrast not only to the models a la Baron and Ferejohn (1989), but also to agenda control models with sincere voting (McKelvey 1976), where an agenda setter could achieve any point in the policy space, or sophisticated voting (Banks 1980, Shepsle and Weingast 1980), where the set of attainable policies is only limited to the Banks set or the uncovered set, respectively. Note also that policy outcomes implied by our pure-strategy equilibria are very different from the results obtained by Bernheim, Rangel and Rayo (2006), where the last proposer can capture all or almost all of the benefits, or Kalandrakis (2004; 2007), where in the long run every proposer is able to take all.

We also show that there is a second class of stationary equilibria characterized by mixed proposal strategies. In those equilibria, the agenda setter randomizes among possible winning coalitions and strategically designs a series of policy proposals so that he eventually captures almost all of the benefits similar to Kalandrakis (2007). However, we show that if legislatures need to make a decision on whether to discuss a policy ("put in on the agenda") these equilibria disappear.

We finally extend the core model to address not only distributional issues but also efficiency properties. When policy efficiency is compared, the institution that allows the possibility of reconsideration always dominates the institution with closed-rule bargaining. The possibility of reconsideration can be interpreted as lack of commitment by the agenda setter. Whereas it has been commonly agreed that lack of commitment by policymakers is a general source of policy inefficiency, the model considered here provides a reversed example and suggests the importance to distinguish different types of lack of commitment. ${ }^{6}$

\footnotetext{
${ }^{4}$ For example, see Kalandrakis (2004, 2005), Fong (2006) and Battaglini and Palfrey (2007).

${ }^{5}$ Duggan and Kalandrakis (2007) prove general existence of pure-strategy stationary equilibria for dynamic legislative bargaining games with some suitably assumed randomness.

${ }^{6}$ The commitment problem was first formally addressed by Kydland and Prescott (1977). More recent political economy studies of government policies include Persson and Svensson (1989), Tabellini and Alesina
} 
The paper is organized as follows. Section 2 describes the model and Section 3 defines a stationary equilibrium. Sections 4 and 5 characterize a class of pure-strategy equilibria for a small legislature with three players and a large legislature with five or more than five players, respectively. Section 6 presents a different class of mixed-strategy equilibria and discusses the issue of equilibrium selection. Section 7 extends the model to include public goods production and addresses welfare implications of the possibility of reconsideration. Section 8 concludes and finally, the Appendix includes all the proofs.

\section{The Model}

Consider a legislature that consists of $n=2 m+1$ players, labeled $i=1,2, \ldots, n$, where $m \in \mathbb{N}$. The legislature must decide on how to divide $\pi$ units of total benefits among the $n$ players, where $\pi \in \mathbb{N}$ is exogenously given. The policy space is finite and denoted by $X=\Delta_{\pi}^{n} \equiv\left\{x \in \mathbb{Z}_{+}^{n}: \sum_{i=1}^{n} x_{i}=\pi\right\}$. Given any policy $x=\left(x_{1}, x_{2}, \ldots, x_{n}\right) \in X$, player $i$ receives $x_{i}$ units of benefits and derives a utility of $u_{i}(x)=x_{i}$.

There is one agenda setter in the legislature. Assume this position is occupied by player 1. The agenda setter is conferred the sole power to make policy proposals from the policy space during a legislative session. All other players, $i \neq 1$, are referred to as voters.

The legislature selects a policy over the course of potentially multiple rounds of proposal making, where the number of rounds depends on exogenous factors and the decision made by the setter. Activities prior to each round $t$ establish a default policy $d_{t} \in X$. In each round $t$, once reached, the agenda setter can choose to make a proposal $x_{t}^{\prime} \in X$ or pass the proposal round. A "pass" is directly modeled as a proposal $x_{t}^{\prime}=d_{t}$, to simplify the mathematical formulation. The proposal, once made, is then put to an immediate vote against $d_{t}$. If it is approved by majority rule, it replaces $d_{t}$ as the default policy and $d_{t+1}=x_{t}^{\prime}$. If it is not approved, the default policy remains the same and $d_{t+1}=d_{t}$. As the legislative session commences, an initial default $d_{1} \in X$ is exogenously given. The policy that survives as default till the end of the session is implemented.

Whereas Bernheim, Rangel and Rayo (2006) assume a finite and fixed number of proposal rounds, the last proposal round is not predetermined in the model considered here. (1990), Besley and Coate (1998), and Acemoglu and Robinson (2001), to name only a few. See Acemoglu (2003) for a comprehensive survey of the commitment literature in political economy. 
The legislative session may end endogenously at round $t$, if the prevailing default $d_{t}$ is such that the setter will choose to pass any possible round $t^{\prime} \geq t$. The session may also be terminated exogenously after any proposal round $t$ with probability $1-\delta$, where $\delta \in[0,1)$ is the probability that the agenda setter will get the opportunity to reconsider the policy that emerges from round $t$.

We interpret $\delta$ as a parameter of the legislative institution, since various congressional rules, unmodeled here, may affect the likelihood of chances for reconsideration. For example, a $\delta=0$ is associated with a one-shot legislative bargaining under a closed rule (Baron and Ferejohn 1989). This paper focuses on institutions with $\delta \in[0,1)$ sufficiently large. ${ }^{7}$

\section{Equilibrium Definition}

This paper focuses the analysis on stationary equilibria. ${ }^{8}$ In any proposal round $t \in \mathbb{N}$, the only payoff-relevant state variable is the prevailing default $d_{t} \in X$, which will be the policy outcome if not replaced by any new proposal in the rest of the legislative session. The legislature thus faces an identical collective choice problem in proposal rounds $t$ and $t^{\prime} \neq t$, if the prevailing default policies in those two rounds are identical. Sationarity implies that the players condition their strategies only on the prevailing default. From now on, the subscript $t$ for proposal round is dropped from the notations.

Let $\sigma: X \rightarrow P(X)$ be the mixed proposal strategy played by the agenda setter, where $P(X)$ is the space of probability measures over $X$. In particular, $\sigma(d, x)$ denotes the probability that the agenda setter proposes a policy $x \in X$ given a prevailing default $d \in X$.

Let $U_{i}(x)$ be the expected utility of player $i$ if a policy $x$ is approved. With probability $1-\delta$ the legislative session is exogenously terminated and this player receives a utility of $u_{i}(x)$. With probability $\delta$ the agenda setter has a chance to revisit the policy issue and makes a new policy proposal according to the mixed strategy $\sigma$. In this case, player $i$ receives

\footnotetext{
${ }^{7}$ In principle, the probability of session continuation needs not be stationary over proposal rounds. For example, in the model of Bernheim, Rangel and Rayo (2006), $\delta_{t}=1$ for all $t<T$, and $\delta_{t}=0$ for all $t \geq T$, where $T$ is the fixed number of proposal rounds.

${ }^{8}$ See Baron and Ferejohn (1989) and Austen-Smith and Banks (2005) for justifications of stationary equilibria in the legislative bargaining games. See Maskin and Tirole (2001) and the references therein for more general discussions.
} 
an expected utility of $\sum_{x^{\prime}} \sigma\left(x, x^{\prime}\right) U_{i}\left(x^{\prime}\right)$. Thus,

$$
U_{i}(x)=(1-\delta) u_{i}(x)+\delta \sum_{x^{\prime}} \sigma\left(x, x^{\prime}\right) U_{i}\left(x^{\prime}\right)
$$

We refer to $U_{i}: X \rightarrow \mathbb{R}$ as the value function of player $i$.

Following the definition of the value function, $U_{i}(d)$ is the reservation value of player $i$ with a prevailing default $d \in X$, where the reservation value is defined as the player's expected utility if the prevailing default remains at the end of the current proposal round.

We make two assumptions regarding how the players break indifference.:

Assumption 1. Any player votes against a policy proposal if and only if passage of the proposal makes him strictly worse off.

Assumption 2. The agenda setter never makes any policy proposal that is destined to be vetoed by a majority of voters. This assumption can be justified by an infinitesimal cost incurred on the agenda setter whenever he makes a policy proposal which is different from the prevailing default. Therefore, in those situations where the agenda setter cannot improve his expected utility by proposal making, he simply lets the prevailing default remain, or equivalently, "proposes" the default policy, which will be approved unanimously.

The agenda setter maximizes his expected utility by proposal making. Any policy alternative is politically feasible if, as a proposal it can be approved by a majority of players. By Assumption 2, the maximization problem of the agenda setter is subject to the constraint of political feasibility. By Assumption 1, this feasibility constraint is equivalent to an incentive compatibility constraint that a majority of players are weakly better off with the proposed policy than with the prevailing default. To sum up, for any prevailing default $d \in X$, any policy $x^{*} \in X$ that the agenda setter may propose with a strictly positive probability must solve

$$
\begin{aligned}
\max _{x^{\prime} \in X} & U_{1}\left(x^{\prime}\right) \\
\text { s.t. } & \left|\left\{i: U_{i}\left(x^{\prime}\right) \geq U_{i}(d)\right\}\right| \geq \frac{n+1}{2}(=m+1),
\end{aligned}
$$

where $|\cdot|$ denotes the number of elements in a set.

We are now ready to define a legislative equilibrium.

Definition 1 A legislative equilibrium is a proposal strategy $\sigma$ and a set of value functions $\left\{U_{i}\right\}_{i=1}^{n}$ such that: 
1. Given $\sigma, U_{i}(x)$ satisfies equation (1) for any $i$.

2. Given $\left\{U_{i}\right\}_{i=1}^{n}, \sigma\left(d, x^{*}\right)>0$ only if $x^{*}$ solves problem (2) of the agenda setter.

The key messages of this paper are based on a class of legislative equilibria with pure strategies. In particular,

Definition 2 A pure-strategy legislative equilibrium is a policy rule $f: X \rightarrow X$ and a set of value functions $\left\{U_{i}\right\}_{i=1}^{n}$ such that $\sigma$ and $\left\{U_{i}\right\}_{i=1}^{n}$ constitute a legislative equilibrium, where $\sigma(d, f(d))=1$ for all $d \in X$.

Consider any pure-strategy legislative equilibrium with policy rule $f$ (assuming its existence). For any $d \in X$, let $f^{0}(d) \equiv d$ and $f^{t}(d) \equiv f\left(f^{t-1}(d)\right)$ for all $t \in \mathbb{N}$. For the policy issue considered in this paper, there exists some equilibrium in which for some $d \in X$, $f^{t}(d) \neq f^{t-1}(d)$ for all $t \in \mathbb{N}$. In other words, for some initial default the legislative session never ends endogenously along the equilibrium path. ${ }^{9}$ In this paper, we ignore the discussion on those equilibria in which the setter never stops proposal making until the session is exogenously terminated. Those equilibria can be eliminated if a tiny proposal cost is suitably assumed. Instead, for any legislative equilibrium considered here, there exists $T \in \mathbb{N}$ such that, for all $d \in X, f^{t}(d)=f^{t-1}(d)$ for all $t \geq T$. We refer to a policy $\widehat{x} \in X$ as the final policy outcome resulting from an initial default $d \in X$, if $f(\widehat{x})=\widehat{x}$ and there exists $\widehat{t} \in \mathbb{N}$ such that $f^{\widehat{t}}(d)=\widehat{x}$.

A preliminary analysis shows that, except for rare cases, the policy outcome in any equilibrium for one-shot legislative bargaining under a closed rule cannot be the final policy outcome in a pure-strategy legislative equilibrium for the game that allows the possibility of reconsideration with $\delta \in[0,1)$ sufficiently large. This observation is presented in the first proposition.

Proposition 1 Let $\widehat{f}$ be the policy rule in any pure-strategy legislative equilibrium for the game with $\delta=0$. Consider the game in which $\delta>0$. In any legislative equilibrium with policy rule $f, f(\widehat{f}(d)) \neq \widehat{f}(d)$ for all $d \in X$ such that $0 \leq\left|\left\{i \neq 1: d_{i}=0\right\}\right| \leq m-1$.

\footnotetext{
${ }^{9}$ For example, assume $n=3, \pi=1$ and the policy space is $\Delta_{1}^{3}=\left\{z^{1}, z^{2}, z^{3}\right\}$, where $z^{i}$ is such that $z_{i}^{i}=\pi$ and $z_{j}^{i}=0$ for all $j \neq i$. There exists a legislative equilibrium with policy rule $f$ such that $f\left(z^{1}\right)=z^{1}$, $f\left(z^{2}\right)=z^{3}$, and $f\left(z^{3}\right)=z^{2}$. Assume the initial default is $d=z^{2}$. Then $f^{t}(d)=z^{2}$ for any $t$ even and $f^{t}(d)=z^{3}$ for any $t$ odd.
} 
The proof is presented in the Appendix.

The next two sections analyze the games for a small legislature with three players and for a large legislature with any odd $n \geq 5$ players, respectively.

\section{A Legislature with Three Players}

This section considers a legislature with three players and characterizes a class of purestrategy legislature equilibria.

Proposition 2 Assume $n=3, \pi \in \mathbb{N}, X=\Delta_{\pi}^{3}$ and $\delta \in[0,1)$ sufficiently large. There exists a pure-strategy legislative equilibrium $\left(f,\left\{U_{i}\right\}_{i=1}^{3}\right)$ such that:

1. For all $d \in Y, f(d)=d$, where

$$
Y \equiv\left\{x \in X: x_{2}=x_{3}\right\}
$$

is the set of absorbing states.

2. For all $d \in X \backslash Y, f(d) \in Y$. The agenda setter makes at most one proposal along the equilibrium path.

3. For all $d \in X$,

$$
f_{i}(d)= \begin{cases}\pi-2 e(d), & \text { if } i=1, \\ e(d), & \text { if } i \neq 1\end{cases}
$$

and

$$
U_{i}(d)= \begin{cases}(1-\delta) d_{1}+\delta(\pi-2 e(d)), & \text { if } i=1, \\ (1-\delta) d_{i}+\delta e(d), & \text { if } i \neq 1,\end{cases}
$$

for some $e(d) \in \mathbb{Z}_{+}$such that $\underline{e}(d) \leq e(d) \leq \bar{e}(d)$, where

$$
\begin{aligned}
& \underline{e}(d) \equiv \min \left\{d_{2}, d_{3}\right\}, \\
& \bar{e}(d) \equiv \max e^{\prime} \in \mathbb{Z}_{+} \text {s.t. } e^{\prime} \leq \frac{1}{2}\left(d_{2}+d_{3}\right) .
\end{aligned}
$$

The proof is presented in the Appendix.

Part 1 of the proposition states that there exist policies which as default the agenda setter is either unwilling to or unable to replace by any other policy. Moreover, given any policy in this set of absorbing states, the two voters receive the same amount of benefits. Part 2 says that if the agenda setter ever makes a proposal, he chooses from policies in the set of 
absorbing states regardless of the initial default. Therefore, reconsideration never happens in equilibrium although it is permitted. Therefore, it is the possibility of reconsideration, not its actual occurrence, that changes the nature of legislative bargaining.

Part 3 of the proposition presents the policy rule and value functions in equilibrium. In particular, the agenda setter seeks voting support from the voter with a lower reservation value and expropriates the other voter to the extent that the two voters receive equal amount of benefits. In a setup of dynamic legislative bargaining, it is not necessarily trivial to assess which voter is the cheaper one to buy. In the special case with three players, this critical voter is the one who receives less from the default.

As an example, consider any $d \in X$ such that $d_{2}<d_{3}$. Note that $d_{2}=\underline{e}(d) \leq e(d) \leq$ $\bar{e}(d) \leq d_{3}$. Therefore, the bounds on the reservation values are

$$
\begin{aligned}
& U_{2}(d)=(1-\delta) d_{2}+\delta e(d) \in(e(d)-1, e(d)], \\
& U_{3}(d)=(1-\delta) d_{3}+\delta e(d) \in[e(d), e(d)+1),
\end{aligned}
$$

for $\delta \in[0,1)$ sufficiently large. In equilibrium, the agenda setter offers $e(d)$ units of benefits to both voters. Among all policy alternatives in the set of absorbing states, this is one that just satisfies player 2 by his reservation value and maximizes the expected utility of the agenda setter.

\section{Incentives of the Players}

A central question is: Why does the agenda setter have to offer both voters an equal amount of benefits?

Consider the same example. Suppose that the agenda setter offers $e(d)$ units of benefits to player 2 but only some $e^{-}<e(d)$ units to player 3 . In this case, player 3 is expropriated and he must vote against the proposal. We claim that play 2 will also vote against it. To see why, consider counter-factually, what would happen if player 2 approved the policy $x^{-} \equiv\left(\pi-e(d)-e^{-}, e(d), e^{-}\right)$. With probability $1-\delta$ the session would end immediately and $x^{-}$is implemented. With probability $\delta$, the agenda setter would have a chance to reconsider the policy issue and propose a new policy $\left(\pi-2 e\left(x^{-}\right), e\left(x^{-}\right), e\left(x^{-}\right)\right)$. This policy satisfies player 3 by his reservation value so will be approved in majority voting. Note that

$$
e\left(x^{-}\right) \leq \bar{e}\left(x^{-}\right) \leq \frac{1}{2}\left(e(d)+e^{-}\right)<e(d)
$$


Therefore by accepting policy $x^{-}$, player 2 would be eventually expropriated since the policy would be reconsidered. Anticipating such an adverse consequence, player 2 will always vote against the proposal of $x^{-}$, even though according to this proposal he is given $e(d) \geq d_{2}$ units of benefits. By this argument, player 2 will not allow the agenda setter to expropriate the other voter too much so that, in the rest of the legislative session, the other voter will have a lower reservation value than player 2 and look more attractive for the agenda setter to ally with. As a consequence, the best the setter can do for himself is to offer both voters equal amount of benefits and just satisfy the voter who is given less by the default.

Although the voters derive utilities only from the benefits they receive, they form indirect preferences over the distribution of benefits. In the above example, player 2 strictly prefers $(\pi-2 e(d), e(d), e(d))$ to $\left(\pi-e(d)-e^{-}, e(d), e^{-}\right)$, even though either policy, if materializes, gives him $e(d)$ units of benefits. Through the dynamic link of an evolving default, distribution of benefits affects distribution of bargaining power in the rest of the legislative session.

Therefore, the two voters effectively demand a more egalitarian allocation of resources between them. In particular, any voter does not allow the other voter to be sufficiently expropriated by the agenda setter. This demand for "fairer allocations" results from selfinterested voters who want to improve their long-term bargaining positions. It does not depend on primitive preferences for fair allocations. In a model of collective decision over legislative procedures, this insight may have implications for the existence of minority rights and benefits in legislatures.

On the other hand, the agenda setter has an incentive to expropriate as much as possible. The fact that the agenda setter proposes less benefits for himself than what he would do under a closed rule is driven by the fact that he is constrained by the voters who constrain him in equilibrium. As a consequence, the agenda setter has limited ability to expropriate the voter whose vote is not needed.

\section{Multiple Equilibria}

Part 3 of the proposition also implies the existence of multiple equilibria. For any $d \in X$ such that $\left|d_{2}-d_{3}\right| \geq 2$, multiple values of $e(d)$ are permissible. Those equilibria are 
driven by self-fulling expectations. ${ }^{10}$ Consider a numerical example. Assume $\pi=6$ and $d=(2,3,1)$. Two possible equilibrium policy outcomes are $\widehat{x}^{1}=(4,1,1)$ and $\widehat{x}^{2}=(2,2,2)$. First, suppose everyone believes that, if the default $(2,3,1)$ remains and the legislative session continues, policy $\widehat{x}^{1}=(4,1,1)$ will be proposed and approved in the next proposal round. Given this expectation, the reservation values of players 2 and 3 are

$$
\begin{aligned}
& U_{2}(d)=3(1-\delta)+\delta \in(1,2), \\
& U_{3}(d)=(1-\delta)+\delta=1 .
\end{aligned}
$$

Player 3 is the cheaper voter for the setter to buy. The agenda setter has to offer both voters 1 unit of benefits to get a vote from player 3 , and $\widehat{x}^{1}$ is the best the setter can achieve. The fact that the agenda setter proposes $\widehat{x}^{1}$ with the prevailing default $(2,3,1)$ is consistent with the common belief of the players. Second, suppose instead everyone believes that, if the default $(2,3,1)$ remains and the legislative session continues, policy $\widehat{x}^{2}=(2,2,2)$ will be proposed and approved in the next proposal round. Given this expectation, the reservation values of players 2 and 3 are

$$
\begin{aligned}
& U_{2}(d)=3(1-\delta)+2 \delta \in(2,3), \\
& U_{3}(d)=(1-\delta)+2 \delta \in(1,2) .
\end{aligned}
$$

Again player 3 is the cheaper voter, although his reservation value is higher than that in the previous case. With a similar argument, in this equilibrium the agenda setter proposes $\widehat{x}^{2}$ under the prevailing default $(2,3,1)$. The proposal strategy is again consistent with the common belief of the players.

How beliefs are coordinated goes beyond the equilibrium analysis provided in this paper. In principle, legislators may have channels to communicate with one another through policy deliberation or in private negotiations.

\section{Bounds on the Values of Proposal Power}

Not any belief can be supported. In the example above, policy $(6,0,0)$ or $(0,3,3)$ cannot be the equilibrium policy outcome if the initial default is given by $(2,3,1)$. In particular, in any equilibrium the agenda setter gets more than what he receives from the default policy. Moreover, the voter from whom the agenda setter seeks voting support must receive no less

\footnotetext{
${ }^{10}$ See Hassler et al (2003) for another example of multiple equilibria in a political economy model of redistributive policy.
} 
than what he is allocated by the default. The next proposition addresses these properties and implies that Part 3 of Proposition 2 has presented all pure-strategy equilibria such that Parts 1 and 2 of Proposition 2 are satisfied. This section thus completely characterizes a certain class of legislative equilibria.

Proposition 3 Assume $n=3, \pi \in \mathbb{N}, X=\Delta_{\pi}^{3}$ and $\delta \in[0,1)$ sufficiently large. In any equilibrium such that $f(d) \in Y$ for all $d \in X$ and $f(d)=d$ for all $d \in Y$,

$$
\pi-2 \bar{e}(d) \leq f_{1}(d) \leq \pi-2 \underline{e}(d)
$$

This proposition is an implication of stationarity. In particular, in any pure-strategy legislative equilibrium, for any $i, U_{i}(f(d)) \geq U_{i}(d)=(1-\delta) d_{i}+\delta U_{i}(f(d))$ if and only if $U_{i}(f(d)) \geq d_{i}$. Therefore, among the equilibria such that $f(f(d))=f(d)$ for all $d \in X$, $U_{i}(f(d)) \geq U_{i}(d)$ if and only if $f_{i}(d) \geq d_{i}$. The fact that the agenda setter must weakly prefer his proposal to the default thus implies that $f_{1}(d) \geq d_{1} \geq \pi-2 \bar{e}(d)$. The requirement that at least one voter must approve the proposal, together with the restriction that $f(d) \in$ $Y$, implies that $f_{i}(d) \geq \underline{e}(d)=\min \left\{d_{1}, d_{2}\right\}$ for all $i \neq 1$. Therefore, $f_{1}(d) \leq \pi-2 \underline{e}(d)$.

Proposition 3 identifies the bounds on the possible values of proposal power in the class of equilibria characterized in this section. As a noteworthy feature, even in cases in which proposal power has maximal strength, its value is still constrained. Specifically, the value of proposal power in the model is in general smaller that what is implied by a one-shot legislative bargaining game under a closed rule.

Finally, depending on the initial default, the agenda setter may not be the one who receives the most benefits in equilibrium. Indeed, the agenda setter may be the player who gets the least amount. This, however, happens only if the agenda setter is sufficiently disadvantaged by the initial default. For example, assume $\pi=8$ and $d=(1,3,4)$. The unique equilibrium policy outcome is $(2,3,3)$. This is consistent with episodes in which parties with insufficient representation take control of the government. Possible cases include minority and caretaker governments.

\section{A Legislature with Five or More Than Five Players}

This section characterizes pure-strategy equilibria for a legislature with any odd $n \geq 5$ players. The intuitions established in the previous section carry over to the case with a 
larger legislature. Before results are stated in the next proposition, additional notations are defined to simplify the presentation. For any policy $x \in X$ and any $e^{\prime} \in \mathbb{Z}_{+}$, let $L\left(x, e^{\prime}\right) \equiv\left\{i \neq 1: x_{i} \leq e^{\prime}\right\}$ be the set of voters who receive no more than $e^{\prime}$ units of benefits from $x$, and $K\left(x, e^{\prime}\right) \equiv\left\{i \neq 1: x_{i}=e^{\prime}\right\}$ be the set of voters who receive exactly $e^{\prime}$ units of benefits. ${ }^{11}$

Proposition 4 Assume odd $n \geq 5, \pi \in \mathbb{N}, X=\Delta_{\pi}^{n}$ and $\delta \in[0,1)$ sufficiently large. There exists a legislative equilibrium $\left(f,\left\{U_{i}\right\}_{i=1}^{n}\right)$ such that:

1. For all $d \in Y, f(d)=d$, where $Y \equiv z^{1} \bigcup_{e^{\prime}=1}^{\infty} Y\left(e^{\prime}\right)$ is the set of absorbing states, $z^{1} \equiv(\pi, 0, \ldots, 0)$ and, for all $e^{\prime} \in \mathbb{N}$,

$$
Y\left(e^{\prime}\right) \equiv\left\{x \in X:\left|K\left(x, e^{\prime}\right)\right|=m+1 \text { and }|K(x, 0)|=m-1\right\} .
$$

2. For all $d \in X \backslash Y, f(d) \in Y$. The agenda setter makes at most one proposal along the equilibrium path.

3. For all $d \in X, f(d)$ is such that (i) $f(d) \in Y(e(d))$, (ii) $f_{1}(d)=\pi-(m+1) e(d)$, and (iii) $|K(f(d), e(d)) \cap L(d, e(d))| \geq m$, and

$$
U_{i}(d)= \begin{cases}d_{i}, & \text { if } d \in Y, \\ (1-\delta) d_{1}+\delta[\pi-(m+1) e(d)], & \text { if } d \in X \backslash Y \text { and } i=1, \\ (1-\delta) d_{i}+\delta e(d), & \text { if } d \in X \backslash Y \text { and } i \in K(f(d), e(d)), \\ (1-\delta) d_{i}, & \text { if } d \in X \backslash Y \text { and } i \in K(f(d), 0),\end{cases}
$$

for some $e(d) \in \mathbb{Z}_{+}$such that $\underline{e}(d) \leq e(d) \leq \bar{e}(d)$, where

$$
\begin{aligned}
& \underline{e}(d) \equiv \min e^{\prime} \in \mathbb{Z}_{+} \text {s.t. }\left|L\left(d, e^{\prime}\right)\right| \geq m, \\
& \bar{e}(d) \equiv e^{\prime} \in \mathbb{Z}_{+} \text {s.t. } e^{\prime} \leq \frac{\pi-d_{1}}{m+1} .
\end{aligned}
$$

The proof is presented in the Appendix.

This proposition is stated in parallel to its counterpart, Proposition 2. Part 1 states that there exist policies which as default the agenda setter is either unwilling to or unable to replace by any other policy. The ideal policy $z^{1}$ of the agenda setter is obviously one of the absorbing states since the agenda setter will have no incentive to change it. For any other policy in the set of absorbing states, some $m+1$ voters receive equal and positive

\footnotetext{
${ }^{11}$ If this is helpful, $L$ is for Less Than Or Equal To and $K$ is for Equal To.
} 
amount of the benefits and the other $m-1$ voters receive nothing. ${ }^{12}$ Part 2, again, asserts that reconsideration does not occur in equilibrium.

Part 3 of the proposition presents the policy rule and value functions in equilibrium. Although it appears complicated, a pure-strategy equilibrium can be constructed by a simple algorithm Consider any $d \in X$. Suppose everyone believes that, if the default remains, in the subsequent proposal round the a policy $f^{b}(d)$ will be proposed from the set of $Y\left(e^{b}(d)\right)$ for some $e^{b}(d) \in \mathbb{Z}_{+}$. Any credible belief $e^{b}(d)$ has to be such that $(m+1) e^{b}(d) \leq \pi-d_{1}$ and that there exists at least $m$ voters who receive no more than $e^{b}(d)$ units from the default $d$. Then discuss two cases. ${ }^{13}$ Case 1 . If $m \leq|K(d, 0)| \leq 2 m$ and $e^{b}(d)=0$, then the agenda setter proposes his ideal policy $z^{1}$. This is because the agenda setter can obtain voting support from every voter $i$ in $K(d, 0)$, whose reservation value is $U_{i}(d)=0$. Case 2. Suppose $e^{b}(d)>0$. Due to the requirement that $e(d) \geq \underline{e}(d),\left|L\left(d, e^{b}(d)\right)\right| \geq m$ and $U_{i}(d)=(1-\delta) d_{i}+\delta f_{i}^{b}(d) \leq e^{b}(d)$ for all $i \in L\left(d, e^{b}(d)\right)$. The inequality is established since $d_{i} \leq e^{b}(d)$ and $f_{i}^{b}(d) \in\left\{0, e^{b}(d)\right\}$. In this case, the equilibrium proposal strategy is to offer $e(d)=e^{b}(d)$ to $m+1$ voters, among which $m$ voters have to be in the set of $L\left(d, e^{b}(d)\right)$. This guarantees that those $m$ voters in $L\left(d, e^{b}(d)\right)$ vote for the proposal, since with the actually proposed policy,

$$
\begin{aligned}
& U_{i}(f(e))=e(d) \\
\geq & U_{i}(d)=(1-\delta) d_{i}+\delta e(d)
\end{aligned}
$$

for all $i \in L(d, e(d))$.

As a numerical example, assume $n=5(m=2), \pi=10$ and $d=(0,1,2,3,4)$. Possible equilibrium outcomes include $(4,2,2,2,0),(4,2,2,0,2),(1,3,3,3,0),(1,3,3,0,3)$, $(1,3,0,3,3)$ and $(1,0,3,3,3)$. These outcomes are associated with $e(d) \in\{2,3\}$, and the agenda setter receives 4 units or 1 unit of benefits, respectively.

The class of pure-strategy equilibria presented in Proposition 4 features three properties that are absent in the other legislative bargaining models. First, although $m$ votes are needed to pass a new policy, in equilibrium $m+1$ voters receive positive amounts of benefits.

\footnotetext{
${ }^{12}$ Recall that the legislature consists of one agenda setter and $2 m$ voters. The agenda setter can form a simple majority with $m$ voters.

${ }^{13} \mathrm{~A}$ belief $e^{b}(d)$ is not consistent with any $d \in X$ such that $0 \leq|K(d, 0)| \leq m-1$. In this case, for any voter $i \notin K(d, 0), U_{i}(d)=(1-\delta) d_{i} \in(0,1)$. Those voters constitute a majority coalition and they strictly prefer the default to $z^{1}$, which is the only element in $Y(0)$. This case is thus dropped from the discussion.
} 
Second, all the $m+1$ voters who receive benefits receive an equal amount. Third, some, or even all, of the voters who vote for the proposal in equilibrium may receive more benefits than they would from the initial default. Reconsider the example with $d=(0,1,2,3,4)$. In the equilibrium such that the policy outcome is $(4,2,2,2,0)$, players 2 and 3 vote for the proposal. Whereas player 3 is indifferent, player 2's benefits are raised from 1 unit to 2 units. In the equilibrium such that the policy outcome is $(1,3,3,0,3)$, again players 2 and 3 vote for the proposal. Moreover, both supporters of the proposed policy receive more than from the default.

All three new properties result from the possibility of reconsideration. Out of fear that the agenda setter may exploit his proposal power to expropriate the voters with low reservation values in the future, any voter $i$ accepts a policy $x^{*} \in X$ only if, with $x^{*}$ as default, the number of voters who look more attractive for the agenda setter as potential future allies is less than $m$. In other words, with $x^{*}$ as default, the reservation value of any supporter of this policy must be ranked among the bottom $m$.

In an equilibrium characterized by Proposition 4, a policy proposal is usually not symmetric to the voters. In other words, voters who receive the same from the default may be treated differently by the agenda setter. This is evident in the following numerical example. Assume $n=5, \pi=50$, and $d=(10,10,10,10,10)$. The agenda setter needs two votes from the voters to pass a new policy but cannot fully expropriate the other two. That said, the agenda setter has to offer three out of four voters 20 units of benefits and expropriates the fourth. Therefore, the setter can play a pure strategy and propose either $\widetilde{x}^{2}=(20,0,10,10,10), \widetilde{x}^{3}=(20,10,0,10,10), \widetilde{x}^{4}=(20,10,10,0,10)$, or $\widetilde{x}^{5}=(20,10,10,10,0)$. In any of these policies, one voter, whose identity is known, is targeted for expropriation. Intuitively, imagine that in equilibrium a group of voters, for example players 2,3 , and 4 , form a coalition and commit to protect the benefits for one another. They will not accept any policy by which any of their coalition members is offered less than 2 units of benefits. Given this, the agenda setter can only expropriate player 5 . The commitment is credible since those players are weakly better off keeping their promises given any best responses of the agenda setter. The intuition obtained for a legislature with three players is thus extended to cases for a legislature of a larger size. In particular, when $m$ votes are needed to pass a new policy, $m+1$ voters bound themselves together and protect the benefits for one another against the agenda setter. 
The reader may ask whether randomization of policies $\left\{\widetilde{x}^{i}\right\}_{i=2}^{5}$ is also a possible equilibrium strategy. Such randomization treats all voters equally, but it cannot be an equilibrium strategy. Suppose all players anticipate that if the default remains in the subsequent proposal round the setter will play a mixed strategy and randomize the policies $\left\{\widetilde{x}^{i}\right\}_{i=2}^{5}$. Then the reservation value of any voter $i$ is

$$
U_{i}(d)=10(1-\delta)+\delta\left[\frac{3}{4}(10)\right] \in(7,8],
$$

and the setter can pass any policy $\widehat{x}^{k}, k \neq 1$, such that $\widehat{x}_{k}^{k}=0, \widehat{x}_{j}^{k}=8$ for all $j \neq 1, k$, and $\widehat{x}_{1}^{k}=26$. The expectations are not consistent with the equilibrium strategy. In a similar manner, if all players anticipate that in the default remains in the subsequent proposal round the setter will randomize the policies $\left\{\widehat{x}^{i}\right\}_{i=2}^{5}$, then the reservation values of all voters turn out to be even smaller so that the agenda setter is able to pass a more expropriating policy than any of $\left\{\widehat{x}^{i}\right\}_{i=2}^{5}$. A characterization of mixed-strategy equilibria is discussed in Section 6.

Part 3 of Proposition 4 implies the existence of multiple equilibria, as illustrated in the previous examples. Those multiple equilibria are driven by self-fulling expectations. The next proposition identifies the bounds on the values of proposal power. Its proof is omitted since it follows the same logic as the proof of its counterpart, Proposition 3. In cases in which proposal power has its maximal strength, its value is still unambiguously smaller than the value of proposal power under a closed rule.

Proposition 5 Assume odd $n \geq 5, \pi \in \mathbb{N}, X=\Delta_{\pi}^{n}$ and $\delta \in[0,1)$ sufficiently large. In any equilibrium such that $f(d) \in Y$ for all $d \in X$ and $f(d)=d$ for all $d \in Y$,

$$
\pi-(m+1) \bar{e}(d) \leq f_{1}(d) \leq \pi-(m+1) \underline{e}(d) .
$$

\section{Equilibrium Selection}

Besides the pure-strategy equilibria characterized in the previous sections, there exist (other) legislative equilibria with mixed proposal strategies. In those equilibria, if the legislative session continues for at least two proposal rounds, it is guaranteed that the agenda setter takes all the benefits and leaves nothing to the others, regardless of the initial default. The equilibrium outcome is reminiscent of the results in Bernheim, Rangel and Rayo (2006), 
and Kalandrakis $(2004 ; 2007)$. The next proposition presents the results for a legislature with three players.

Proposition 6 Assume $n=3, \pi \in \mathbb{N}, X=\Delta_{\pi}^{3}$ and $\delta \in[0,1)$ sufficiently large. There exists a legislative equilibrium $\left(\sigma,\left\{U_{i}\right\}_{i=1}^{3}\right)$ such that:

1. The only absorbing state is the ideal policy of the agenda setter, denoted by $z^{1}$. In other words, $\sigma(d, d)=1$ if and only if $d=z^{1}$.

2. For any $d, x^{*} \in X$, if $\sigma\left(d, x^{*}\right)>0$ then $\sigma\left(x^{*}, z^{1}\right)=1$. The agenda setter makes at most two proposals along the equilibrium path.

3. For any $d \in X$ such that $d_{2} d_{3}=0$,

$$
\sigma\left(d, x^{*}\right)= \begin{cases}1, & \text { if } x^{*}=z^{1}, \\ 0, & \text { if } x^{*} \neq z^{1},\end{cases}
$$

and

$$
U_{i}(d)= \begin{cases}(1-\delta) d_{1}+\delta \pi, & \text { if } i=1, \\ (1-\delta) d_{i}, & \text { if } i \neq 1 .\end{cases}
$$

4. For any $d \in X$ such that $d_{2} d_{3} \neq 0$,

$$
\sigma\left(d, x^{*}\right)= \begin{cases}\frac{1}{2}-\frac{d_{2}-d_{3}}{2 \delta\left(d_{2}+d_{3}\right)}, & \text { if } x^{*}=\left(d_{1}, \pi-d_{1}, 0\right), \\ \frac{1}{2}+\frac{d_{2}-d_{3}}{2 \delta\left(d_{2}+d_{3}\right)}, & \text { if } x^{*}=\left(d_{1}, 0, \pi-d_{1}\right), \\ 0, & \text { otherwise, }\end{cases}
$$

and

$$
U_{i}(d)= \begin{cases}\left(1-\delta^{2}\right) d_{1}+\delta^{2} \pi, & \text { if } i=1 \\ (1-\delta)\left[\frac{1}{2}(1+\delta)\left(\pi-d_{1}\right)\right], & \text { if } i \neq 1\end{cases}
$$

5. For any $d \in X$ such that $d_{2} d_{3}>0, U_{i}(d)<d_{i}$ for all $i \neq 1$. That is, in the beginning of the legislative session the expected utilities of both voters are strictly lower than their utilities had the initial default materialized.

The proof is presented in the Appendix. Part 1 of the proposition states that, in the presented equilibrium, the only policy that can persist as default is the policy $z^{1}$ that gives all the benefits to the agenda setter. Part 2 says that, for any initial default, the policy converges to $z^{1}$ within at most two proposal rounds. Along the equilibrium path, reconsideration occurs either once or never. 
Parts 3 and 4 describe the mixed proposal strategies and the value functions. The agenda setter is able to pass his ideal policy right away if nothing is given to some voter by the default. Otherwise, the setter strategically manipulates the sequence of proposals so that he is able to pass his ideal policy in the second proposal round, if the legislative session reaches there. In the interim stage, i.e., the first proposal round, the agenda setter takes away the benefits from one voter and give them to the other one. This is done with randomization so that, with positive probability, each voter may be given nothing at the end of round one.

As an example, assume $\pi=6$ and $d=(2,3,1)$. In the equilibrium described above, with probability $\frac{1}{2}\left(1-\frac{1}{2 \delta}\right) \simeq \frac{1}{4}$, the setter seeks voting support from player 2 , who is the voter favored by the default, and with probability $\frac{1}{2}\left(1+\frac{1}{2 \delta}\right) \simeq \frac{3}{4}$, the setter seeks voting support from player 3 , who is the voter disadvantaged by the default. The setter gives 2 units of the benefits to himself, and the other 4 units to whoever he chooses to buy. The policy outcome at the end of round one is either $(2,4,0)$ or $(2,0,4)$. With probability $\delta$ the legislative session continues and the agenda setter can pass his ideal policy $(6,0,0)$. Observe that, if both voters anticipate the mixed proposal strategies in the very beginning of the session, their reservation values would be the same as $2\left(1-\delta^{2}\right)$. This sets the ground for the agenda setter to randomize between the two voters.

Finally, Part 5 implies that, except for rare cases in which the setter can immediately pass his ideal policy, both voters would be strictly better off if the legislative bargaining game was not played and the initial default was directly implemented. In the previous example, the value of the game for player $i \neq 1$ is $U_{i}(d)=2\left(1-\delta^{2}\right)<d_{i}$, given that $\delta \in[0,1)$ is sufficiently large. This property plays a crucial role when equilibrium selection is discussed later.

Mixed-strategy equilibria also exist, in a similar fashion, for a legislature with five or more than five players. They are presented in the next proposition.

Proposition 7 Assume odd $n \geq 5, \pi \in \mathbb{N}, X=\Delta_{\pi}^{n}$ and $\delta \in[0,1)$ sufficiently large. There exists a legislative equilibrium $\left(\sigma,\left\{U_{i}\right\}_{i=1}^{n}\right)$ such that:

1. The only absorbing state is the ideal policy of the agenda setter, denoted by $z^{1}$. In other words, $\sigma(d, d)=1$ if and only if $d=z^{1}$.

2. The agenda setter makes at most two proposals along the equilibrium path. 
3. For all $d \in X$ such that $m \leq|K(d, 0)| \leq 2 m, \sigma\left(d, x^{*}\right)=1$ only if $x^{*}=z^{1}$.

4. For all $d \in X$ such that $0 \leq|K(d, 0)| \leq m-1, \sigma\left(d, x^{*}\right)>0$ only if $m \leq\left|K\left(x^{*}, 0\right)\right| \leq$ $2 m$.

5. For any $d \in X$ such that $0 \leq|K(d, 0)| \leq m-1$,

$$
\left|\left\{i: U_{i}(d)<d_{i}\right\}\right| \geq \frac{n+1}{2}(=m) .
$$

That is, in the beginning of the legislative session the expected utilities of at least a majority of players are strictly lower than their utilities had the initial default materialized.

This proposition is a restricted version of Proposition 2 of Kalandrakis (2007), who constructs stationary equilibria for a game with a continuous distributive policy space, an arbitrary odd $n \geq 5$ players, an arbitrary $\delta \in[0,1)$, and an arbitrary stationary probability of setter selection in every proposal round. In those equilibria, mixed strategies are played and the policy converges to the ideal policy of the agenda setter in three proposal rounds. Interested readers are referred to the appendix of Kalandrakis (2007). The proof of Proposition 7 is thus omitted.

The mixed-strategy equilibria, again, are driven by self-fulfilling expectations. In equilibrium, regardless of the initial default, all players anticipate that, if the default remains, the agenda setter will play mixed strategies and eventually implement his ideal policy. Given such a common belief, all voters must have very small reservation values and are willing to accept a policy proposal that delivers very small expected utilities to them and eventually carries out their expectation. This equilibrium thus exhibits an extreme form of the "power to propose".

So far two classes of legislative equilibria have been established for the game considered here. In one class of legislative equilibria, the agenda setter plays a pure proposal strategy, a group of voters protect the benefits for one another in order to secure their bargaining positions in the subsequent proposal rounds, and the value of proposal power is constrained. In the other class of legislative equilibria, the agenda setter plays mixed proposal strategies and has a nearly dictatorial power. The two classes of legislative equilibria display opposite features. 
The obvious next question is whether and on what grounds we can choose between the two classes of equilibria.

We here present an argument that suggests that the pure-strategy legislative equilibria should be observed. Notice that in all legislatures the policy decision-making process is proceeded by a procedural stage where the legislature decides on whether to deliberate on a given topic. Recall that in the mixed-strategy equilibria a majority of legislators expects to be strictly worse off compared to the case where no legislative deliberation takes place.

Formally, consider an augmented game with one additional stage before legislative bargaining begins. In that pre-bargaining stage, an initial default $d \in X$ is exogenously given and one player (e.g., player 1 ) is randomly selected as the proposer. ${ }^{14}$ The legislature must decide by majority rule whether or not to enter the legislative bargaining process specified in Section 2. The choice is denoted by $\theta \in\{0,1\}$. If $\theta=1$, then the legislative bargaining game commences. Instead if $\theta=0$, then the legislative session ends immediately and the initial default $d$ is implemented. Part 5 of Propositions 6 and 7 assert that, in the mixed-strategy equilibria in which the setter has a nearly dictatorial power, more than onehalf of the voters are better off with the initial default than with the equilibrium policy outcome of the legislative bargaining game. Therefore, if the players anticipate that the setter will play expropriating mixed strategies, $\theta=0$ will be chosen by majority rule in the pre-bargaining stage. In other words, conditional on the occurrence of legislative bargaining over some policy issue, the final policy outcome should be consistent with the prediction of some pure-strategy equilibrium but not a mixed-strategy one.

In conclusion, it is more reasonable to select those pure-strategy equilibria (in Sections 4 and 5) as predictions of the theory of legislative bargaining. This view can be tested by experiments and by congressional data. We leave these empirical investigations for future research.

\section{$7 \quad$ Policy Efficiency and Possibility of Reconsideration}

The model of distributive politics allows us to identify the value of proposal power but does not address welfare implications. This section extends the model so that the size of total benefits is also a policy variable to be determined in the legislature. We then examine how

\footnotetext{
${ }^{14}$ It does not matter whether the agenda setter is chosen before or after the pre-bargaining stage.
} 
a legislative institution that allows the possibility of reconsideration may improve policy efficiency.

Consider a legislature with three players. They must jointly produce benefits that they can divide and consume. A policy $x=\left(x_{1}, x_{2}, x_{3}\right)$ specifies not only allocation but also size of the total benefits. The policy space is therefore $X=\bigcup_{\pi=0}^{\infty} \Delta_{\pi}^{3}$, where $\Delta_{\pi}^{3}$ is the distributive policy space for three players to divide $\pi$ units of total benefits. Public production is costly. The cost function is assumed to be quadratic and given by

$$
C(x)=\frac{1}{2} \kappa\left(\sum_{i=1}^{3} x_{i}\right)^{2}
$$

where $\kappa$ is a constant marginal cost of production. Each player $i$ is assumed to share equally the production cost, and for any policy $x \in X$, derive a utility of

$$
u_{i}(x)=\mu x_{i}-\frac{1}{3} C(x)
$$

where $\mu$ is a common marginal utility of benefit consumption. ${ }^{15}$

The initial default is assumed to be $d=(0,0,0)$. That is, if no agreement is made in the legislature, there will be no production and consumption of the benefits.

If the policy was chosen by a benevolent dictator, the size of total benefits would be $\pi^{*} \equiv \frac{\mu}{\kappa}$, at which level marginal social cost of production is equal to marginal utility of benefits consumption. Here, a policy is made through the political process of legislative bargaining.

In a one-shot legislative bargaining under a closed rule, the agenda setter needs to satisfy one voter, for example $j$, by his reservation value $U_{j}((0,0,0))=0$ and can fully expropriate the other voter. By proposing any policy $x$ associated with $\pi_{x} \equiv \sum_{i=1}^{3} x_{i}$ units of total benefits, the setter can take $\left[\pi_{x}-\frac{1}{3 \mu} C\left(\pi_{x}\right)\right]$ units. There is overproduction of the benefits in equilibrium since the setter only internalizes the costs paid by himself and voter $j$.

If reconsideration is allowed and $\delta \in[0,1)$ is sufficiently large, by the argument in Section 4, the agenda setter has to offer both voters an equal amount of benefits whatever level of the total benefits production. This is because each voter is induced to protect the benefits of the other voter in order to secure his own long-term bargaining position in the legislature. Therefor, by proposing any policy $x$ associated with $\pi_{x}$ units of total benefits, the setter can take no more than $\left[\pi_{x}-2\left(\frac{1}{3 \mu} C\left(\pi_{x}\right)\right)\right]$ units, otherwise neither voter would accept the

\footnotetext{
${ }^{15}$ For technical convenience, assume that the values of $\mu$ and $\kappa$ are such that $\frac{\mu}{\kappa}$ is a multiple of 24 .
} 
policy proposal. Any politically feasible policy $x$ thus requires the setter to internalize fully all costs and gains of benefits production.

Policy outcomes and welfare implications are compared in the next proposition for games with $\delta=0$ and with $\delta \in[0,1)$ sufficiently large.

Proposition 8 Assume $n=3, X=\bigcup_{\pi=0}^{\infty} \Delta_{\pi}^{3}, d=(0,0,0)$.

1. Consider the bargaining institution under a closed rule, i.e., with $\delta=0$. In any closedrule equilibrium with policy rule $\widehat{f}$,

$$
\begin{aligned}
& \sum_{i=1}^{3} \widehat{f}_{i}(d)=\frac{3}{2} \pi^{*}, \\
& \widehat{f}_{1}(d)=\frac{9}{8} \pi^{*},
\end{aligned}
$$

and there are distinct $j, k \neq 1$ such that

$$
\begin{aligned}
& \widehat{f}_{j}(d)=\frac{3}{8} \pi^{*}, \\
& \widehat{f}_{k}(d)=0 .
\end{aligned}
$$

2. Consider the bargaining institution with the possibility of reconsideration and with $\delta \in[0,1)$ sufficiently large. There exists a legislative equilibrium with policy rule $f$ such that:

$$
\begin{aligned}
& \sum_{i=1}^{3} f_{i}(d)=\pi^{*}, \\
& f_{1}(d)=\frac{2}{3} \pi^{*}, \\
& f_{2}(d)=f_{3}(d)=\frac{1}{6} \pi^{*} .
\end{aligned}
$$

3. The agenda setter strictly prefers the bargaining institution with a closed rule to the one with the possibility of reconsideration and with $\delta \in[0,1)$ sufficiently large. In particular,

$$
\begin{aligned}
& u_{1}(\widehat{f}(d))=\frac{7}{8} \mu \pi^{*} \\
>\quad & u_{1}(f(d))=\frac{1}{2} \mu \pi^{*} .
\end{aligned}
$$

4. The bargaining institution with the possibility of reconsideration and with $\delta \in[0,1)$ sufficiently large dominates the one under a closed rule in policy efficiency. In particular,

$$
\begin{gathered}
\sum_{i=1}^{3} u_{i}(f(d))=\frac{1}{2} \mu \pi^{*} \\
>\quad \sum_{i=1}^{3} u_{i}(\widehat{f}(d))=\frac{3}{8} \mu \pi^{*} .
\end{gathered}
$$


The proof of Part 2 is presented in the Appendix.

Parts 1 and 2 of the proposition summarize the preceding analysis. Parts 3 states that the agenda setter is always better off if he could commit to making a proposal once and for all than if he is allowed to reconsider an approved policy. On the other hand, Part 4 says that social welfare defined by aggregate utility is unambiguously improved with the possibility of reconsideration.

Proposition 8 can be generalized for a legislature with any odd $n \geq 5$ players. ${ }^{16}$ In equilibrium there is always overproduction of the benefits regardless of the bargaining institution, but the same welfare comparison holds. For a $\delta \in[0,1)$ sufficiently large, the agenda setter internalizes production costs paid by one more voter than he would do with $\delta=0$. Therefore, with the possibility of reconsideration the extent of overproduction is restrained and aggregate utility is enhanced. Paradoxically granting some political actor, here the agenda setter, more power may improve social welfare.

The possibility of reconsideration can be interpreted as lack of commitment by the agenda setter. While it is commonly agreed that lack of commitment by policymakers is a source of inefficiency, to the contrary, the model considered here provides a counterexample: Lack of commitment by an agenda setter with persistent proposal power may lead to less unequal allocations and more efficient policy outcomes. This suggests the importance to distinguish different types of commitment technologies.

\section{Constitutional Design}

The model in this paper allows an analysis of constitutional design. Here a "constitution" refers to a set of rules by which a collective decision is made. ${ }^{17}$

Formally, suppose there is a constitutional stage preceding legislative bargaining. In the constitutional stage the legislature must decide whether or not to allow reconsideration in the political process of policymaking. In particular, assume the legislature is restricted to choosing from $\delta \in\{0, \bar{\delta}\}$, where $\bar{\delta} \in[0,1)$ is sufficiently large. Constitutional parameter $\delta=0$ refers to one-shot legislative bargaining under a closed-rule, whereas $\delta=\bar{\delta}$ refers to a bargaining institution in which reconsideration is allowed. The choice of $\delta$ depends on whether the identity of the agenda setter is known in the constitutional stage.

\footnotetext{
${ }^{16} \mathrm{~A}$ formal proof adds notational complication but not new insights and is omitted.

${ }^{17}$ See Mueller (2003) for a survey of earlier studies in the literature. See Aghion and Bolton (2003), Aghion, Alesina and Trebbi (2004), and Harstad (2005) for recent developments.
} 
Suppose that before a constitutional choice is made player 1 has been recognized as agenda setter in the legislative bargaining stage. Then except for rare cases player 1 will strictly prefer $\delta=0$ to $\delta=\bar{\delta}$ and the player whose vote is needed by the agenda setter in the legislative bargaining stage will be indifferent between the two constitutional choices. As a consequence, the legislative procedure that forbids reconsideration can be chosen by majority voting.

Suppose instead that the constitutional choice is made under a veil of ignorance, in the sense that the identity of the agenda setter in the legislative stage is unknown. In this case the legislature will unanimously agree to choose $\delta=\bar{\delta}$. Reconsideration is allowed since the possibility of reconsideration enhances aggregate utility as well as ex ante utility of each player.

\section{Concluding Remarks}

This paper proposes a new analytical framework of legislative bargaining. A central idea is that policymaking is finalized only after all players with agenda control have no more incentive to replace the default policy. The setup, we believe, captures important features of legislative decision-making such as an endogenous default and the possibility of reconsideration without a predetermined last proposal round. We identify a class of pure-strategy equilibria in which a group of voters protect the benefits for one another against the agenda setter. The model is tractable and can be easily applied to dynamic models or embedded in a public finance setup.

Baron and Ferejohn (1989) suggest that the possibility of amendments could also lead to reduced proposal power and possibly a supermajority voting coalition. With possibility of amendments, any agenda setter has to consider the fact that some of the other legislators may be recognized to move or to amend his proposal. The initial agenda setter thus faces a trade-off between increasing his own share of the benefits and increasing the probability that his proposal will be moved and accepted. This induces the agenda setter to care possibly more of the other legislators than a bare majority. The distribution of benefits is thus more even and the value of proposal power more constrained. Our paper suggests a different mechanism. With the possibility of reconsideration, whereas the agenda setter wants to expropriate as much as possible, the other legislators with no proposal power have 
incentive to take care of some of the others. Any legislator with no agenda control could prevent their bargaining power from being weakened in the future by protecting the others from being sufficiently expropriated by the agenda setter. Therefore, granting the agenda setter more power implies a less valuable power. In other words, the amendment process discussed by Baron and Ferejohn (1989) focuses on the incentives of proposers, whereas our theory focuses on nonproposers.

There are various natural extensions of the model. First, we may want to study the trade-offs between proposal incentives and exploitation risk in a model with reconsideration. Consider a voter $i$ that has to decide on whether to accept a proposal that exploits some other voter $j$. If $i$ does not expect to be the proposer in the future our results will hold, however, if he does he may want to vote to accept because this will improve his bargaining position as a future proposer. With random proposer recognition there will be a trade-off between these two effects that can be studied in a more general model.

Another extension would be to replace the agenda setter by a gatekeeper. We define a gatekeeper as the player who is conferred the veto right to block any policy proposal made by some others and at the same time able to propose a new policy in some situations. The sequence of events in the game can be modified as follows: There is an initial default and one player is randomly assigned to be a gatekeeper. The players then are able to make policy proposals in turn. A player can choose to pass his turn if proposing a policy does not make himself better off. Once a proposal is made, it has to be approved by the gatekeeper and then voted on against the default by majority rule. A passed proposal becomes the new default in future proposal rounds. Legislative interaction ceases after all players pass their proposal turns. The final default policy is then implemented. In a model like this, we would be able to compare the respective values of proposal power and gate-keeping power.

This analytical framework could also be incorporated into fuller developed models of public finance and macroeconomic policy choice. ${ }^{18}$ As recent empirical studies on political economy and comparative constitutions have established various stylized facts and raised new questions about how political institutions shape dynamics of policy, we expect fruitful insights from such an approach.

\footnotetext{
${ }^{18}$ See Diermeier and Fong (2007) for an application of the model that accounts for the patterns of government spending dynamics in multi-party parliamentary countries.
} 


\section{Appendix: Proofs}

Proof of Proposition 1. Step A. A one-shot legislative bargaining under a closed rule is associated with a game with $\delta=0$. For $\delta=0$, in any pure-strategy legislative equilibrium with policy rule $\widehat{f}$, for any $d \in X$ there exists $M(d) \subseteq\left\{j \neq 1: d_{j} \leq \widehat{e}(d)\right\}$, where $\widehat{e}(d) \equiv \min e^{\prime} \in \mathbb{Z}$ s.t. $\left|\left\{j \neq 1: d_{j} \leq e^{\prime}\right\}\right| \geq m$, such that $|M(d)|=m$, and

$$
\widehat{f}_{i}(d)= \begin{cases}\pi-\sum_{i \in M(d)} d_{i}, & \text { if } i=1, \\ d_{i}, & \text { if } i \in M(d), \\ 0, & \text { otherwise. }\end{cases}
$$

This is a standard result proved by Baron and Ferejohn (1989).

Step B. For any $\delta \in[0,1)$, in any legislative equilibrium with proposal strategy $\sigma$, $\sigma\left(z^{1}, z^{1}\right)=1$, where $z^{1} \equiv(\pi, 0, \ldots, 0)$. In other words, if the prevailing default is the ideal policy of the agenda setter, it remains till the end of the legislative session. This claim is obvious since $U_{1}(x)<U_{1}\left(z^{1}\right)$ for all $x \neq z^{1}$.

Step C. Assume $\delta>0$. Consider any pure-strategy legislative equilibrium with policy rule $f$. Suppose that there exists some $d \in X$ such that $0 \leq\left|\left\{j \neq 1: d_{j}=0\right\}\right| \leq m-1$ and $f(\widehat{f}(d))=\widehat{f}(d)$. Then $m \leq\left|\left\{j \neq 1: \widehat{f}_{j}(d)=0\right\}\right| \leq 2 m-1$. Moreover, for all $i \in$ $\left\{j \neq 1: \widehat{f}_{j}(d)=0\right\}, U_{i}(\widehat{f}(d))=U_{i}\left(z^{1}\right)=0$ and $U_{1}(\widehat{f}(d))<U_{1}\left(z^{1}\right)$. In any proposal round, if $\widehat{f}(d)$ is the prevailing default, $z^{1}$ is politically feasible and the agenda setter is strictly better off proposing $z^{1}$ than remaining the default. This is a contradiction.

Proof of Proposition 2. Parts 1 and 2 are implied by Part 3 of the proposition. The proof of Part 3 is based on construction and verification of an equilibrium.

Step A. Given the policy rule described in the proposition, we first verify that the value functions satisfy equation (1). This step is straightforward.

Step B. Given the value functions described in the proposition, we then verify that, for all $d \in X, f(d)$ solves problem (2) of the agenda setter. To do so, take any $d \in X$.

Claim 1. There exists $j \neq 1$ such that $U_{j}(f(d)) \geq U_{j}(d)$, i.e., $f(d)$ is politically feasible. Proof. Note that $e(d) \geq \underline{e}(d) \equiv \min \left\{d_{2}, d_{3}\right\}$. Let $j \neq 1$ be such that $d_{j}=\min \left\{d_{2}, d_{3}\right\}$. Then

$$
\begin{aligned}
& U_{j}(f(d))=e(d) \\
\geq & U_{j}(d)=(1-\delta) \min \left\{d_{2}, d_{3}\right\}+\delta e(d) .
\end{aligned}
$$


Claim 2. For all $x^{\prime} \in X$, either $U_{1}\left(x^{\prime}\right) \leq U_{1}(f(d))$, or $U_{i}\left(x^{\prime}\right)<U_{i}(d)$ for all $i \neq 1$.

Proof. Discuss four cases.

Case 1. Take any $x^{\prime} \in X$ such that $e\left(x^{\prime}\right)>e(d)$. Then

$$
\begin{aligned}
& U_{1}\left(x^{\prime}\right)=(1-\delta) x_{1}^{\prime}+\delta\left(\pi-2 e\left(x^{\prime}\right)\right) \\
< & U_{1}(f(d))=\pi-2 e(d)
\end{aligned}
$$

for all $\delta \in[0,1)$ sufficiently large.

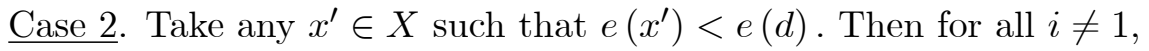

$$
\begin{aligned}
& U_{i}\left(x^{\prime}\right)=(1-\delta) x_{1}^{\prime}+\delta e\left(x^{\prime}\right) \\
<\quad & U_{i}(d)=(1-\delta) x_{1}^{\prime}+\delta e(d)
\end{aligned}
$$

for all $\delta \in[0,1)$ sufficiently large.

Case 3. Take any $x^{\prime} \in X$ such that $e\left(x^{\prime}\right)=e(d)$ and $x_{1}^{\prime} \leq \pi-2 e(d)$. Then $U_{1}\left(x^{\prime}\right) \leq$ $U_{1}(f(d))$.

Case 4. Take any $x^{\prime} \in X$ such that $e\left(x^{\prime}\right)=e(d)$ and $x_{1}^{\prime}>\pi-2 e(d)$. Then $e\left(x^{\prime}\right) \leq$ $\bar{e}\left(x^{\prime}\right)<e(d)$. This is a contradiction.

Proof of Proposition 4. Parts 1 and 2 are implied by Part 3 of the proposition. The proof of Part 3 is based on construction and verification of an equilibrium.

Step A. Given the policy rule described by (i)-(iii) in part 3 of the proposition, we first verify that the value functions satisfy equation (1). This step is straightforward.

Step B. Given the value functions described in the proposition, we then verify that, for any $d \in X, f(d)$ solves problem (2) of the agenda setter. To do so, take any $d \in X$.

Claim 1. There exists a coalition $M(d)$ of voters such that $|M(d)| \geq m$ and $U_{i}(f(d)) \geq$ $U_{i}(d)$ for all $i \in M(d)$, i.e., $f(d)$ is politically feasible.

Proof. Let $M(d)=|K(f(d), e(d)) \cap L(d, e(d))|$. By property (iii) of the policy rule, $|M(d)| \geq m$. Moreover,

$$
\begin{aligned}
& U_{i}(f(d))=e(d) \\
\geq & U_{i}(d)=(1-\delta) d_{i}+\delta e(d)
\end{aligned}
$$

for all $i \in M(d)$. The inequality is established since $e(d) \geq d_{i}$ for all $i \in M(d)$. 
Claim 2. For all $x^{\prime} \in X$, either $U_{1}\left(x^{\prime}\right) \leq U_{1}(f(d))$, or there exists a coalition $M_{+}(d)$ of voters, such that $\left|M_{+}(d)\right|=m+1$ and $U_{i}\left(x^{\prime}\right)<U_{i}(d)$ for all $i \in M_{+}(d)$.

Proof. Discuss four cases.

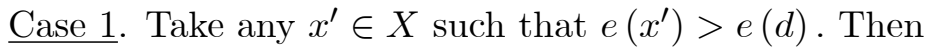

$$
\begin{aligned}
& U_{1}\left(x^{\prime}\right)=(1-\delta) x_{1}^{\prime}+\delta\left(\pi-(m+1) e\left(x^{\prime}\right)\right) \\
< & U_{1}(f(d))=\pi-(m+1) e(d)
\end{aligned}
$$

for all $\delta \in[0,1)$ sufficiently large.

Case 2. Take any $x^{\prime} \in X$ such that $e\left(x^{\prime}\right)<e(d)$. This implies that $e(d) \geq 1$. Since $f(d) \in Y(e(d)),|K(f(d), e(d))|=m+1$. Note that $f_{i}\left(x^{\prime}\right) \in\left\{0, e\left(x^{\prime}\right)\right\}$ and $f_{i}\left(x^{\prime}\right)<e(d)$ for all $i \in K(f(d), e(d))$. Therefore, for all $i \in K(f(d), e(d))$,

$$
\begin{aligned}
& U_{i}\left(x^{\prime}\right)=(1-\delta) x_{1}^{\prime}+\delta f_{i}\left(x^{\prime}\right) \\
<\quad & U_{i}(d)=(1-\delta) d_{1}^{\prime}+\delta e(d)
\end{aligned}
$$

for all $\delta \in[0,1)$ sufficiently large.

Case 3. Take any $x^{\prime} \in X$ such that $e\left(x^{\prime}\right)=e(d)$ and $x_{1}^{\prime} \leq \pi-(m+1) e(d)$. Then $U_{1}\left(x^{\prime}\right) \leq U_{1}(f(d))$.

Case 4. Take any $x^{\prime} \in X$ such that $e\left(x^{\prime}\right)=e(d)$ and $x_{1}^{\prime}>\pi-(m+1) e(d)$. Then $e\left(x^{\prime}\right) \leq \bar{e}\left(x^{\prime}\right)<e(d)$. This is a contradiction.

Proof of Proposition 7. Parts 1, 2, and 5 of the proposition are implied by Parts 3 and 4. The proof of Parts 3 and 4 are based on construction and verification of an equilibrium.

Step A. Given the mixed strategy $\sigma$ described the proposition, we first verify that the value functions satisfy equation (1). This step is straightforward.

Step B. Given the value functions described in the proposition, we then verify that, for all $d \in X$ and $x^{*} \in X$, if $\sigma\left(d, x^{*}\right)>0$ then $x^{*}$ solves problem (2) of the agenda setter. In particular, we verify that (1) $x^{*}$ is politically feasible, and (2) for all $x^{\prime} \neq x^{*}$, either $U_{1}\left(x^{\prime}\right) \leq U_{1}\left(x^{*}\right)$ or $U_{i}\left(x^{\prime}\right)<U_{i}(d)$ for all $i \neq 1$. We discuss this in three cases.

Case 1. Consider $d=z^{1}$. Then observe that, for any $x^{\prime} \neq z^{1}, U_{1}\left(x^{\prime}\right)<\pi=U_{1}(d)$.

Case 2. Consider any $d \neq z^{1}$ such that $d_{2} d_{3}=0$. Without loss of generality, assume $d_{2}=0$ and $d_{3}>0$. Then observe that $z^{1}$ is politically feasible since $U_{2}\left(z^{1}\right)=U_{2}(d)=0$. Moreover, for any $x^{\prime} \neq z^{1}, U_{1}\left(x^{\prime}\right)<\pi=U_{1}\left(z^{1}\right)$. 
Case 3. Consider any $d \in X$ such that $d_{2} d_{3} \neq 0$. Define $\widehat{x}(2) \equiv\left(d_{1}, \pi-d_{1}, 0\right)$. Then observe that $\widehat{x}(2)$ is politically feasible since

$$
\begin{gathered}
U_{2}(\widehat{x}(2))=(1-\delta)\left(\pi-d_{1}\right) \\
>\quad U_{2}(d)=(1-\delta)\left[\frac{1}{2}(1+\delta)\left(\pi-d_{1}\right)\right] .
\end{gathered}
$$

By symmetry, $\widehat{x}(3) \equiv\left(d_{1}, 0, \pi-d_{1}\right)$ is also politically feasible and $U_{1}(\widehat{x}(2))=U_{1}(\widehat{x}(3))$. In the rest of the proof we claim that, for all $x^{\prime} \in\{\widehat{x}(2), \widehat{x}(3)\}$, either $U_{1}\left(x^{\prime}\right) \leq U_{1}\left(\widehat{x}^{\prime}(2)\right)$ or $U_{i}\left(x^{\prime}\right)<U_{i}(d)$ for all $i \neq 1$. Without loss of generality, we only discuss the cases in which $x_{2}^{\prime} \geq x_{3}^{\prime}$.

Case 3-1. Suppose $x_{2}^{\prime} \leq \pi-d_{1}-1$ and $x_{3}^{\prime}=0$. Then $U_{3}\left(x^{\prime}\right)=0<U_{3}(d)$. Moreover, $U_{2}\left(x^{\prime}\right) \leq(1-\delta)\left(\pi-d_{1}-1\right)<U_{2}(d)$ for all $\delta \in[0,1)$ sufficiently large.

Case 3-2. Suppose $x_{2}^{\prime} \geq \pi-\left(d_{1}-1\right)$ and $x_{3}^{\prime}=0$. Then $x_{1}^{\prime} \leq d_{1}-1$ and $U_{1}\left(x^{\prime}\right)-$ $U_{1}(d) \leq(1-\delta)\left[1-\delta\left(\pi-d_{1}\right)\right]<0$ for all $\delta \in[0,1)$ sufficiently large. The last inequality is established by the supposition that $d_{2} d_{3} \neq 0$, i.e., $\pi-d_{1} \geq 2$.

Case 3-3. Suppose $x_{2}^{\prime}+x_{3}^{\prime} \leq \pi-d_{1}-1$ and $x_{3}^{\prime} \geq 1$. Then $U_{i}\left(x^{\prime}\right) \leq(1-\delta)\left(\pi-d_{1}-1\right)<$ $U_{i}(d)$ for all $\delta \in[0,1)$ sufficiently large, for all $i \neq 1$.

Case 3-4. Suppose $x_{2}^{\prime}+x_{3}^{\prime} \geq \pi-d_{1}$ and $x_{3}^{\prime} \geq 1$. Then $x_{1}^{\prime} \leq d_{1}$, and $U_{1}\left(x^{\prime}\right) \leq\left(1-\delta^{2}\right) d_{1}+$ $\delta^{2} \pi=U_{1}(d)$.

Proof of Proposition 8. The proof of Part 2 is based on construction and verification of an equilibrium.

Step A. We first conjecture that the policy rule $f(d)$ solves

$$
\begin{array}{ll}
\max _{x^{\prime} \in X} & u_{1}\left(x^{\prime}\right) \\
\text { s.t. } & u_{2}\left(x^{\prime}\right)=u_{3}\left(x^{\prime}\right) \geq \min \left\{u_{2}(d), u_{3}(d)\right\} .
\end{array}
$$

For any $d \in X$ such that the maximization problem (3) has a unique solution, we claim that $f(f(d))=f(d)$. To prove it, suppose this is not true. Then $u_{1}(f(f(d)))>u_{1}(f(d))$ due to uniqueness of the maximum, and

$$
u_{2}(f(f(d)))=u_{3}(f(f(d))) \geq u_{2}(f(d))=u_{3}(f(d)) \geq \min \left\{u_{2}(d), u_{3}(d)\right\} .
$$

This contradicts the fact that $f(d)$ solves the maximization problem (3). For any $d \in X$ such that the maximization problem (3) has more than one solution, we impose the condition that $f(f(d))=f(d)$ in our conjecture. 
Step B. Given the conjectured policy rule $f$, we thus construct the value functions by (1). In particular, $U_{i}(d)=(1-\delta) u_{i}(d)+\delta u_{i}(f(d))$ for all $i$ and all $d \in X$.

Step C. Given the constructed value functions, we then verify that the conjectured policy rule $f$ solves the maximization problem (2) of the agenda setter. Note that the agenda setter's original problem (2) is different from the maximization problem (3) on which the conjectured policy rule is based. In particular, for any $d, x^{\prime} \in X$, we can show that either (1) $U_{1}\left(x^{\prime}\right) \leq U_{1}(f(d))$ or $(2) U_{i}\left(x^{\prime}\right)<U_{i}(d)$ for all $i \neq 1$. The procedure of the verification is the same as those for Propositions 2 and 4 and thus it is omitted here.

Step D. Finally we are ready to solve the equilibrium policy outcome resulting from the initial default $d=(0,0,0)$. Note that even though we are given a specific initial default policy we still have to guess and verify the policy rule $f$ for all $d \in X$. This is because all the players have to calculate the consequences of the choice of any policy $x^{\prime} \in X$ since any approved policy becomes the new default policy had the legislative session continued. In this final stage, solving $f((0,0,0))$ involves solving the maximization problem $(3)$ over a finite policy space $X$. Potentially, this may require pairwise comparisons, which could be tedious. Here we take a different approach. We first transform and simplify the maximization problem (3) into the following one, assuming a continuous policy space:

$$
\begin{array}{cl}
\max _{x_{2}^{\prime}, x_{3}^{\prime}, \pi^{\prime} \in \mathbb{R}} & \mu x_{1}^{\prime}-\frac{1}{3}\left(\frac{1}{2} \kappa\left(\pi^{\prime}\right)^{2}\right) \\
\text { s.t. } & x_{2}^{\prime}=x_{3}^{\prime}, \\
& x_{1}^{\prime}=\pi^{\prime}-x_{2}^{\prime}-x_{3}^{\prime}, \\
& x_{1}^{\prime} \geq 0, \\
& \mu x_{2}^{\prime}-\frac{1}{3}\left(\frac{1}{2} \kappa\left(\pi^{\prime}\right)^{2}\right) \geq 0 .
\end{array}
$$

Observe that the last weak inequality constraint on $x_{2}^{\prime}$ must be binding, and this constraint also guarantees that $x_{2}^{\prime} \geq 0$. We then solve this transformed maximization problem (4) over a continuous policy space, ignoring the second last inequality constraint. The second-order sufficient conditions are obviously satisfied, whereas the first-order necessary conditions imply that $\pi^{\prime}=\pi^{*}, x_{2}^{\prime}=x_{3}^{\prime}=\frac{1}{6} \pi^{*}$. Since $x_{1}^{\prime}=\frac{2}{3} \pi^{*} \geq 0$, the second last inequality constraint is satisfied. Note that the optimal policy $x^{*} \equiv\left(\frac{2}{3} \pi^{*}, \frac{1}{6} \pi^{*}, \frac{1}{6} \pi^{*}\right)$ of the continuous maximization problem is on the grid point of the finite policy space $X$. Since $x^{*}$ attains the unique maximum in the continuous problem, it also attains the maximum in the maximization problem (3) over the finite policy space $X$. 


\section{References}

[1] Acemoglu, Daron. 2003. "Why Not a Political Coase Theorem? Social Conflict, Commitment and Politics." Journal of Comparative Economics, 31, pp. 620-652.

[2] Acemoglu, Daron and James A. Robinson. 2001. "Inefficient Redistribution." American Political Science Review, 95, pp. 649-661.

[3] Aghion, Philippe, Alberto Alesina, and Francesco Trebbi. 2004. "Endogenous Political Institutions." Quarterly Journal of Economics, 119, pp. 565-612.

[4] Aghion, Philippe and Patrick Bolton. 2003. "Incomplete Social Contracts." Journal of the European Economic Association, 1, pp. 38-67.

[5] Austen-Smith, David and Jeffrey S. Banks. 2005. Positive Political Theory II: Strategy and Structure. University of Michigan Press.

[6] Banks, Jeffrey S. 1985. "Sophisticated Voting Outcomes and Agenda Control," Social Choice and Welfare, 1, pp. 295-306.

[7] Baron, David P. 1996. "A Dynamic Theory of Collective Goods Programs." American Political Science Review, 90: 316-30.

[8] Baron, David P. and John Ferejohn. 1989. "Bargaining in Legislatures." American Political Science Review, 83, pp. 1181-1206.

[9] Baron, David P. and Michael Herron. 2003. "A Dynamic Model of Multidimensional Collective Choice." In Computational Models of Political Economy, Ken Kollman, John H. Miller, and Scott E. Page, ed., MIT Press, pp. 13-47.

[10] Battaglini, Marco and Stephen Coate. 2007. "Inefficiency in Legislative Policy-Making: A Dynamic Analysis." American Economic Review, 97(1), pp. 118-149.

[11] Battaglini, Marco and Stephen Coate. 2008. "A Dynamic Theory of Public Spending, Taxation and Debt." American Economic Review, 98(1), pp. 201-236.

[12] Battaglini, Marco and Thomas Palfrey. 2007. "The Dynamics of Redistributive Politics." Working Paper, Princeton University. 
[13] Bernheim, Douglas, Antonio Rangel, and Luis Rayo. 2006. "The Power of the Last Word in Legislative Policy Making." Econometrica, 74, pp. 1161-1190.

[14] Besley, Timothy and Stephen Coate. 1998. "Sources of Inefficiency in a Representative Democracy." American Economic Review, 88, pp. 139-156.

[15] Diermeier, Daniel and Pohan Fong. 2007. "Policy Persistence in a Multi-party Parliamentary Democracy." In Elhanan Helpman, ed., Political Institutions and Economic Performance. Harvard University Press.

[16] Diermeier, Daniel and Sean Gailmard. 2006. "Self-Interest, Inequality, and Entitlement in Majoritarian Decision-Making." Quarterly Journal of Political Science, 1(4), pp. $327-350$.

[17] Diermeier, Daniel and Roger B. Myerson. 1994. "Bargaining, Veto Power, and Legislative Committees." CMSEMS Working Paper No.1089, Northwestern University.

[18] Doering, Herbert. 1995. "Time as a Scarce Resource: Government Control of the Agenda." In Doering, Herbert, ed. Parliaments and Majority Rule in Western Europe. New York: St. Martin's Press.

[19] Duggan, John and Tasos Kalandrakis. 2007. "A Dynamic Model of Legislative Bargaining." Manuscript, University of Rochester.

[20] Harstad, Bard. 2005. "Majority Rules and Incentives." Quarterly Journal of Economics, 120(4), pp. 535-568.

[21] Hassler, John, Kjetil Storesletten, José V. Rodríguez Mora and Fabrizio Zilibotti. 2003. "The Survival of the Welfare state." American Economic Review, 93(1), pp. 87-112.

[22] Kalandrakis, Anastassios. 2004. "A Three-Player Dynamic Majoritarian Bargaining Game." Journal of Economic Theory, 16, pp. 294-322.

[23] Kalandrakis, Anastassios. 2007. "Majority Rule Dynamics with Endogenous Status Quo." Working Paper, Wallis Institute of Political Economy.

[24] Knight, Brian. 2005. "Estimating the Value of Proposal Power." American Economic Review, 95(5), pp. 1639-1652. 
[25] Kydland, Finn and Edward Prescott. 1977. "Rues rather than discretion: The Inconsistency of Optimal Plans." Journal of Political Economy, 85, pp. 473-490.

[26] Maskin, Eric and Jean Tirole. 2001. "Markov Perfect Equilibrium I. Observable Actions." Journal of Economic Theory, 100, pp. 191-219.

[27] McKelvey, Richard D. 1976. "Intransitivities in Multidimensional Voting Models and Some Implications for Agenda Control," Journal of Economic Theory, 12, pp. 472-482.

[28] McKelvey, Richard D. 1991. "An Experimental Test of a Stochastic Game Model of Committee Bargaining." In Thomas R. Palfreyed, ed., Laboratory Research in Political Economy. Ann Arbor: University of Michigan Press.

[29] Mueller, Dennis C. 2003. Public Choice III. Cambridge University Press.

[30] Persson, Torsten and Lars Svensson. 1989. "Why a Stubborn Conservative Would Run a Deficit: Policy with Time-inconsistency Preferences." Quarterly Journal of Economics, 104, pp. 325-345.

[31] Shepsle, Kenneth A. and Barry R. Weingast. 1984. "Uncovered Sets and Sophisticated Voting with Implications for Agenda Institutions." American Journal of Political Science, 28, pp. 49-74.

[32] Tabellini, Guido and Alberto Alesina. 1990. "Voting on the Budget Deficit." American Economic Review, 80(1), pp. 37-49. 